\title{
Fire tests on glued-laminated timber beams with specific local material properties
}

\section{Journal Article}

\section{Author(s):}

Fahrni, Reto; Klippel, Michael; Just, Alar; Ollino, Andres; Frangi, Andrea (D)

Publication date:

2019-07

Permanent link:

https://doi.org/10.3929/ethz-b-000216513

Rights / license:

Creative Commons Attribution-NonCommercial-NoDerivatives 4.0 International

Originally published in:

Fire Safety Journal 107, https://doi.org/10.1016/j.firesaf.2017.11.003 


\title{
Fire tests on glued-laminated timber beams with specific local material properties
}

\author{
R. Fahrni ${ }^{\text {a* }}$ \\ M. Klippel ${ }^{\text {a }}$ \\ A. Just ${ }^{\text {b }}$ \\ A. Ollino ${ }^{\mathrm{c}}$ \\ A. Frangi ${ }^{a}$ \\ ${ }^{a}$ ETH Zürich, Stefano-Franscini-Platz 5, 8093 Zürich, Switzerland \\ b Tallinn University of Technology, Ehitajate tee 5, 19086 Tallinn, Estonia \\ ${ }^{c}$ EstKONSULT OÜ, Sõpruse pst 151, 13417 Tallinn, Estonia \\ *Corresponding author: fahrni@ibk.baug.ethz.ch
}

\begin{abstract}
The fire resistance of glued-laminated timber (glulam) beams is usually determined by calculation models or by tests. The evaluation of the fire resistance tests is accompanied by an uncertainty with regard to the timber material properties, which is, however, important to know when comparing the test results to the effective crosssection method according to EN 1995-1-2. The present paper presents therefore for the first time the results of six fire resistance tests with glulam beams with specific local mechanical material properties, such as exact position and dimension of knots, weak sections and finger joints, densities and strength properties of small cells. The tested glulam beams had an approximate height of $250 \mathrm{~mm}$ and reached a fire resistance of up to 68 minutes. The performed fire tests allowed the determination of the zerostrength layer with a higher certainty than investigations performed in the past. Additionally, reference tests at ambient temperature were considered in the evaluation. The determined zero-strength layer was in the range of $7 \mathrm{~mm}$, as given in the current version of EN 1995-1-2 for beams in bending.
\end{abstract}

\section{KEYWORDS}

Fire resistance tests, glued-laminated timber, charring, fire resistance, fire safety, local properties of timber

\section{INTRODUCTION}

Timber members have to fulfil fire resistance criteria when used in structures. Available methods for timber design in fire range from simple to very advanced. Complex analytical or numerical models are intended to be applied in complex cases and reach a high accuracy, whereas simple design methods are easy and fast to use but might lead to a more conservative design of timber structures (Frangi 2013).

In Europe, the effective cross-section method constitutes a simple design method for the engineer in practice to design timber structures for the fire case. The method bases on standard fire exposure (EN 1363-1 (1999), ISO 834-1 (1999)) and is specified in EN 1995-1-2 (2004). Recently, the effective cross-section method was compared with fire test results (Schmid et al. 2014) dating back until the 1960s. On the basis of the extensive experimental investigations on 117 timber members in bending under standard fire exposure, a large variation of the zero-strength layer $d_{0}$ was found. Schmid et al. (2014) concluded that the large variation mainly comes from the lack of the characterization of the material tested in fire and that most of the performed fire tests are of too poor quality or are incomplete to validate the effective cross-section design model. Consequently, Schmid et al. qualified most of the evaluated fire 
resistance tests as 'uncertain' or even 'very uncertain' with respect to the calculation of the zero-strength layer. Thus, only very few test results exist on timber member exposed to fire where the ambient and fire strength properties are determined with sufficient accuracy.

Model- and full-scale fire resistance tests with full-scale timber beams exposed to standard fire together with reference tests at ambient temperature with the same type of loading were performed only in limited investigations, such as Norén (1988), Peter and Gockerl (2006), and Lange et al. (2014). Of these tests, Schmid et al. (2014) classified only six fire tests leading to 'certain' results with respect to the evaluation according to the effective cross-section method.

The current paper presents a fire test series investigating the fire resistance of six glulam beams under 4-point bending and exposed to EN/ISO standard fire exposure. Thereby, specimens with information about local material properties (finger joint location, area of weak sections, timber board density) were tested. The timber boards used to produce the glulam beams had been machine-graded and the gained information was used in the analysis of the fire tests. In the final section of this paper, the fire resistance tests were evaluated using the effective cross-section method according to EN 1995-1-2 and the zero-strength layer $d_{0}$ was determined.

Six spruce glulam beams with well-known local material properties were tested in fire resistance tests. The specimens usually had seven lamellas (finger-jointed timber boards) and approximately the following dimensions [length $X$ height $X$ width]: 3800 $\times 250 \times 158[\mathrm{~mm}]$. The exact dimensions of each tested beam together with further properties are summarized in Table 1. The different dimensions arise from the fact that the specimens were not fabricated just for that test, but instead were cut out of the unaffected parts of much larger beams $(11400 \times 600 \times 158[\mathrm{~mm}])$ previously tested at ambient temperature in a 4-point bending configuration (Stadelmann 2015). The position of the cuts is exemplarily shown in Figure 1, where also the cracks from the preceding 4-point bending test are shown in order to determine if the cut out specimen can be considered 'undamaged'. The lamella heights of the beams tested in fire were $38.5 \mathrm{~mm}$ for the inner lamellas, while the top and bottom lamellas were $25 \mathrm{~mm}$ $( \pm 1 \mathrm{~mm})$ and $36 \mathrm{~mm}( \pm 2 \mathrm{~mm})$ high, respectively.

Table 1 Properties of tested specimens

\begin{tabular}{cccccccc}
\hline Specimen & $\begin{array}{c}\text { Strength } \\
\text { class }^{\mathbf{a}}\end{array}$ & Length & Width & Height & Weight & $\begin{array}{c}\text { Moisture Density } \\
\text { content, } \\
\text { avg. }\end{array}$ & \\
& & & & & & & \\
{$[\mathbf{m m}]$} & {$[\mathbf{m m}]$} & {$[\mathbf{m m}]$} & {$[\mathbf{k g}]$} & {$[\%]$} & {$\left[\mathbf{k g} / \mathbf{m}^{3}\right]$} \\
\hline 1 & GL24h & 3889 & 157 & 254 & 67.06 & 12.6 & 377.9 \\
2 & GL36h & 3749 & 158 & 256 & 73.78 & 12.0 & 428.2 \\
3 & GL36h & 3882 & 158 & 256 & 77.68 & 10.9 & 440.8 \\
4 & GL24h & 3889 & 158 & 253 & 65.40 & 10.9 & 374.8 \\
5 & GL36h & 3874 & 157 & 253 & 78.98 & 10.7 & 458.3 \\
6 & GL36h & 3620 & 157 & 217 & 61.38 & 11.0 & 442.9 \\
\hline
\end{tabular}

${ }^{a}$ Strength class according to prEN 14080 (2009)

To produce the original beams, machine-graded (GoldenEye-706 by MiCROTEC, Giudiceandrea 2005) timber boards of strength grade L25 and L40 according to 
EN 14081-4 (2009) were used. Since not only the grading parameters (E-modulus and knot indicator) of each timber board were recorded, but also the assembly of the beam, exact information about each timber board, each knot cluster and each finger joint is available. Thus, the local material properties of the tested beams are well-known.

The results of the 4-point-bending tests of the original beams are summarized in Stadelmann (2015). A mean bending strength of $f_{\mathrm{m}}=31.2 \mathrm{~N} / \mathrm{mm}^{2}$ and a mean bending stiffness of $E_{\mathrm{m}}=11075 \mathrm{~N} / \mathrm{mm}^{2}$ were determined based on six bending tests on beams of strength class GL24h. For GL36h, a mean bending strength of $f_{\mathrm{m}}=39.8 \mathrm{~N} / \mathrm{mm}^{2}$ and a mean bending stiffness of $E_{\mathrm{m}}=14847 \mathrm{~N} / \mathrm{mm}^{2}$ resulted from six bending tests, too. As mentioned before, unharmed sections at the top ends were then cut out of these beams, whereof six of totally 22 undamaged beams were used for the presented fire tests. They were randomly chosen, but with more beams of higher strength in order to stimulate failure in the finger-joints and possibly gain information about the fingerjoint behavior under fire. Figure 1 shows the position of the cut-out glulam beams as well as an example of available information about the local material properties at ambient temperature.

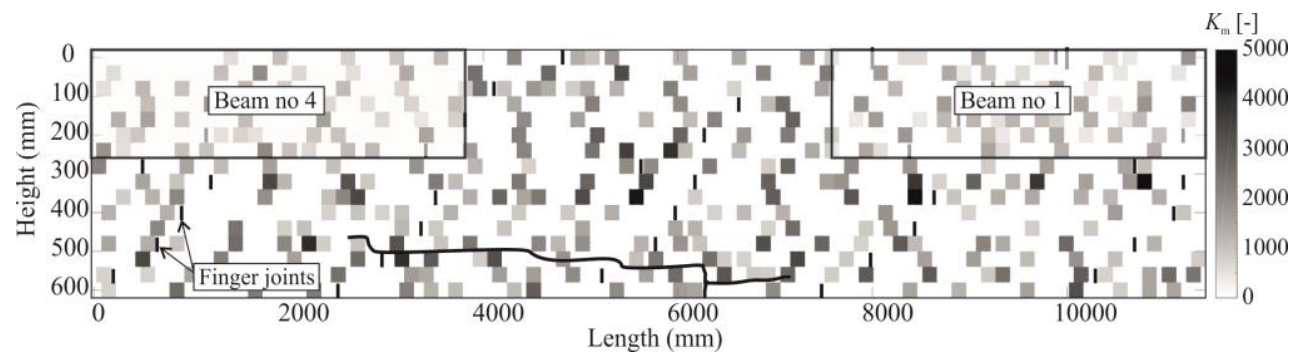

Figure 1 Example of local material properties (here $K_{m}$, knot indicator of GoldenEye grading: the higher the value, the weaker the section) together with finger joints and the position of the cut out beams and the cracks from the preceding 4-point bending test; available for all beams tested in fire

TEST SET-UP AND PROGRAM

Six fire resistance tests were performed in the SP fire laboratory in Stockholm using a model scale furnace with inner dimensions of $1.0 \times 1.0 \times 1.0$ [m]. The fire tests were carried out as 4-point bending tests. Only the middle section of the beams, where the bending moment is constant, was exposed to standard EN/ISO fire on three sides, with the top face being protected by stonewool. The test set-up is shown in Figure 2 and Figure 3. The load was applied at the ends of the beam using hydraulic cylinders, whereas the support details were attached to the furnace's reinforced horizontal edges. During the fire tests, the displacements at different positions (mid-span and supports, in relation to the load-application points) were measured using LVDTs (Linear variable differential transformer). The furnace temperature following the standard EN/ISO curve was measured and controlled with two plate thermocouples located in the middle of the furnace $100 \mathrm{~mm}$ below the bottom side of the test specimen. Figure 4 shows the recorded mean furnace temperatures over time for all beams together with the tolerance according to the standard. Although the fire exposure was too strong for a short period of time for beam 1, the authors do not expect this to have had a strong influence on the charring. 


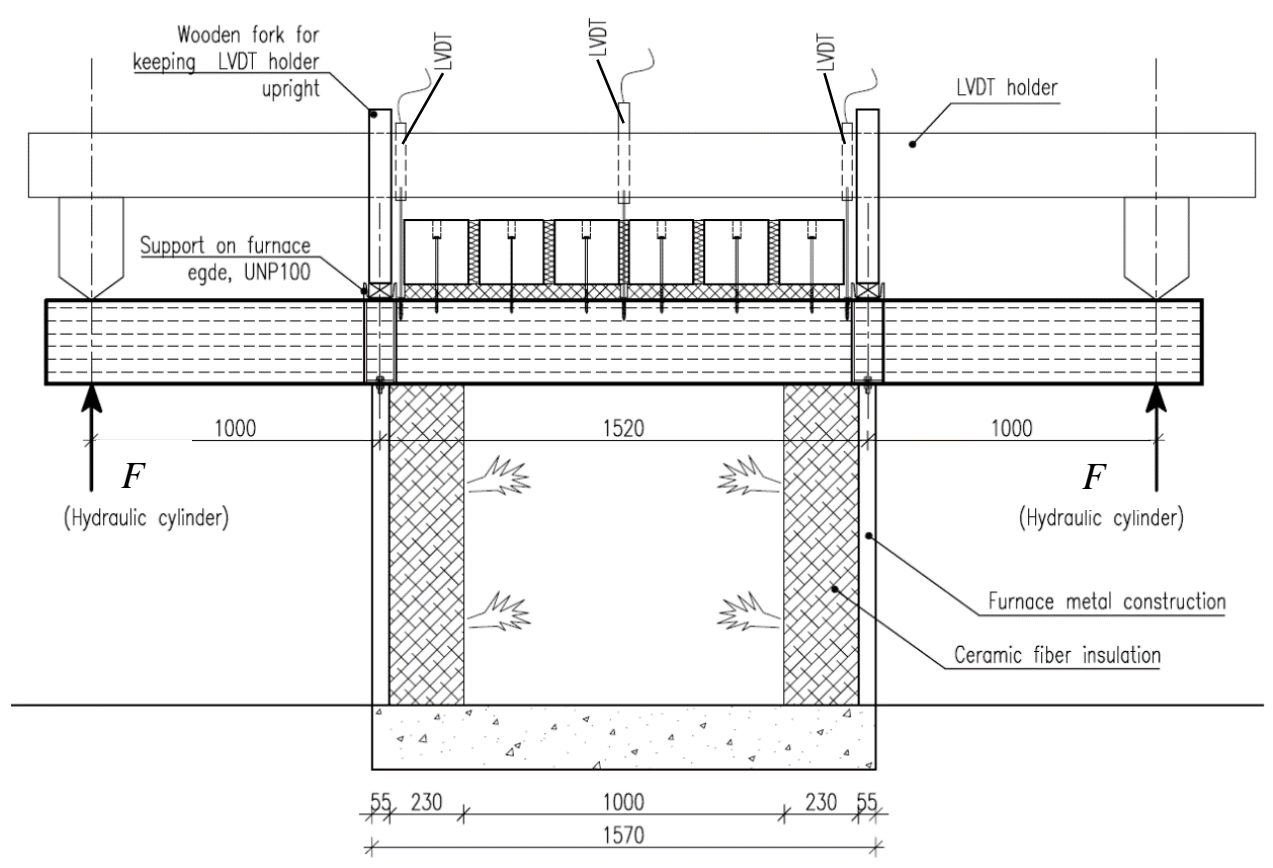

Figure 2 Test set-up: front view; dimensions given in [mm]

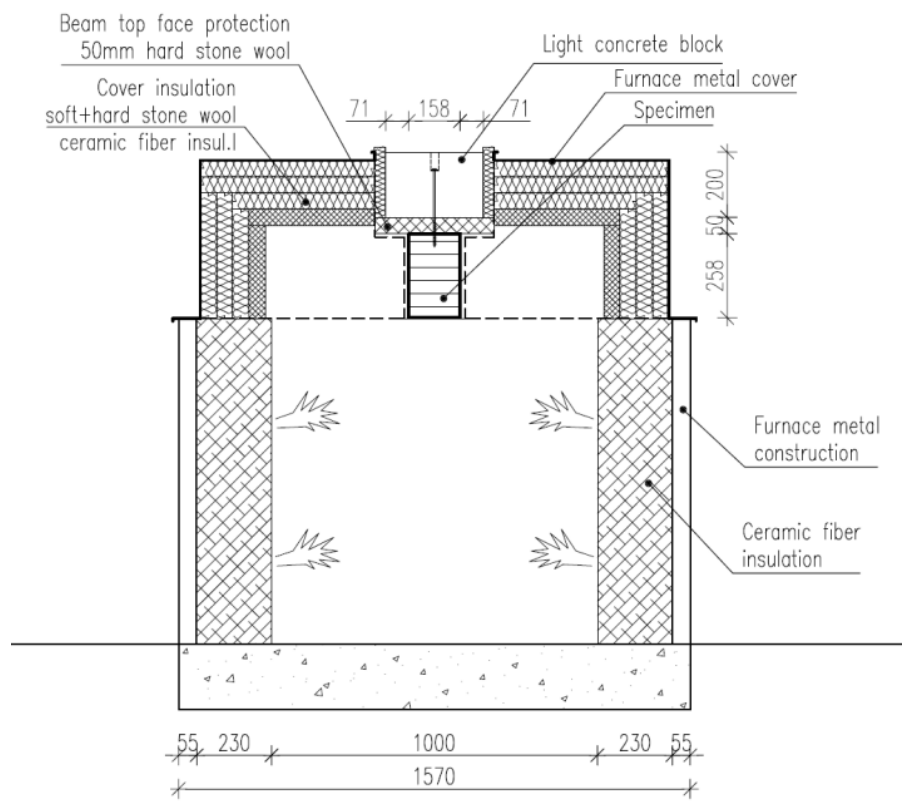

Figure 3 Test set-up: side view; dimensions given in [mm] 


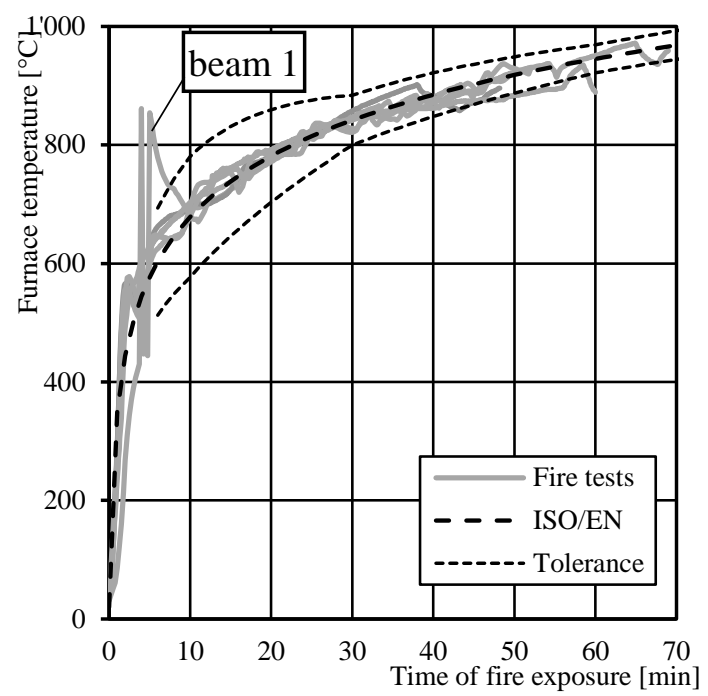

Figure 4. Mean furnace temperatures in the fire tests following the EN/ISO standard fire curve.

Prior to the tests, all beams were examined by measuring moisture content, dimensions, and weight (see Table 1). The beams were loaded with about $30 \%$ of the expected load bearing capacity $F_{\mathrm{u}}$, calculated based on the mean bending strength experienced in the tests of the original beams (see section 2.1) and the specimen's dimensions. One test (beam no 3) was performed with a lower load level of $20 \% F_{\mathrm{u}}$, see Figure 5.

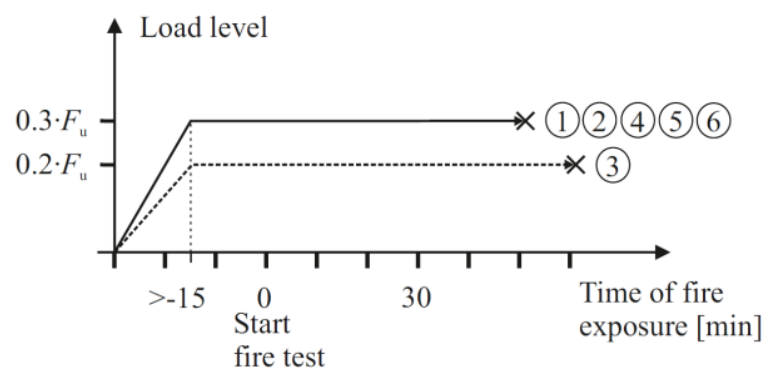

$F_{u}$ : Ultimate load corresponding to the mean bending strength of the beam at normal temperature

Figure 5. Load levels during fire tests for all six beams

The load was applied at least 15 minutes before the start of the test. The load was kept constant during the fire test providing a constant bending moment in the fire exposed section of the beam. Failure was defined either due to a sudden load drop or when the gradual load decrease due to the decreased stiffness could not be compensated with additional movement of the jacks anymore (see also paragraph 3.3). After failure, the cover of the furnace was removed and the beam extinguished with water (Figure 6). This procedure took less than three minutes.
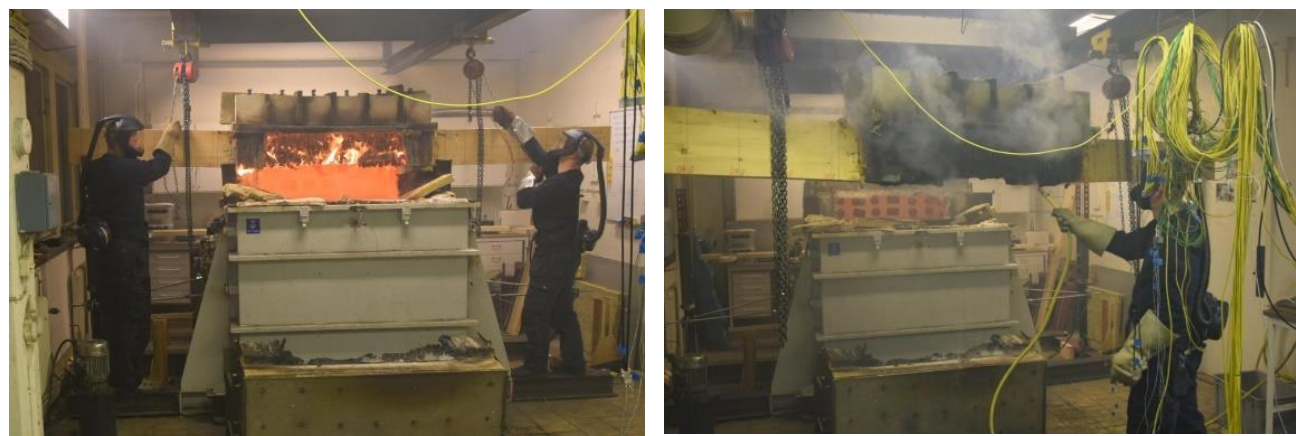

Figure 6. After failure of the specimen, the furnace cover was removed and the glulam beam extinguished with water 


\section{RESULTS OF THE FIRE TESTS}

Table 2 gives an overview of the main results of the fire tests. It should be noted that the results of beams 1 and 2 should only be interpreted in terms of the charring process, as technical problems with the load application occurred. Apart of the fire exposure time $t$, the type of failure and the measured notional charring rate $\beta_{n}$ of all beams is presented. In the following sections, the results of the fire tests are presented and discussed in detail.

Table 2. Overview of fire test results. $F_{u}$ denotes the load bearing capacity calculated with the results from the preceding 4-point bending tests. The failure types are 'clear wood' $(\mathrm{CW})$, 'knot cluster' $(K C)$ and 'finger joint' (FJ).

\begin{tabular}{cccccccc}
\hline No & $\begin{array}{c}\text { Strength } \\
\text { class }^{\text {a }}\end{array}$ & $\begin{array}{c}\text { Load } \\
\text { level }\end{array}$ & $\begin{array}{c}\text { Applied } \\
\text { Load } \boldsymbol{F}\end{array}$ & $\begin{array}{c}\text { Bending } \\
\text { Moment } \\
\boldsymbol{M}_{\boldsymbol{f} \boldsymbol{i}}\end{array}$ & $\begin{array}{c}\text { Fire } \\
\text { exposure } \\
\text { time } \boldsymbol{t}\end{array}$ & $\begin{array}{c}\text { Type of } \\
\text { failure }^{\mathrm{b}}\end{array}$ & $\begin{array}{c}\text { Mean } \\
\text { notional } \\
\text { charring } \\
\text { rate } \boldsymbol{\beta}_{\boldsymbol{n}} \\
{[\mathbf{m m} / \mathbf{m i n}]}\end{array}$ \\
\hline 1 & GL24h & $\left(0.3 F_{u}\right)$ & 16.4 & 16.4 & $00: 52: 00$ & - & 0.78 \\
2 & GL36h & $\left(0.3 F_{u}\right)$ & 20.7 & 20.7 & $00: 49: 15$ & - & 0.74 \\
3 & GL36h & $0.2 F_{\mathrm{u}}$ & 13.9 & 13.9 & $01: 08: 53$ & $\mathrm{CW}$ & 0.68 \\
4 & GL24h & $0.3 F_{\mathrm{u}}$ & 16.0 & 16.0 & $00: 48: 06$ & $\mathrm{CW}+\mathrm{KC}$ & 0.80 \\
5 & $\mathrm{GL36h}^{\mathrm{C}}$ & $0.3 F_{\mathrm{u}}$ & 21.0 & 21.0 & $00: 58: 17$ & $\mathrm{CW}+\mathrm{KC}$ & 0.71 \\
6 & GL36h $^{\mathrm{c}}$ & $0.3 F_{\mathrm{u}}$ & 14.5 & 14.5 & $00: 44: 24$ & $\mathrm{FJ}+\mathrm{KC}$ & 0.70 \\
\hline
\end{tabular}

a according to prEN 14080

${ }^{\mathrm{b}}$ see section 3.1

${ }^{\mathrm{c}}$ lower height than other beams

\subsection{FIRE RESISTANCE AND TYPE OF FAILURE}

Failure of glulam beams exposed to fire can typically be initiated by the following three types:

- Failure in a finger joint section (FJ)

- Failure in a timber section due to a knot cluster (KC)

- Failure in a timber section in a clear wood section $(\mathrm{CW})$

However, it should be noted that the failure type of glulam beams exposed to fire can only be determined after removing the char layer and thus not during the fire test. Moreover, it is impossible to determine the failure type whenever there are multiple cracks visible, as it cannot be determined, which one caused the stopping of the test. After extinguishing the glulam beam with water, the char layer was removed and the beam thoroughly examined. Figure 7 presents an example of the evaluation of the failure mode after knowing the location of failure. In the evaluation, the local material properties were considered, namely the finger joint position and the knot indicator $K_{m}$. The knot indicator was provided by the grading process and ranges from zero if no knots are present to a few thousand with many knots in the cross-section. Thus, the higher the $K_{m}$-value, the weaker the section is with respect to strength characteristics of the clear wood surrounding the knot cluster.

The failure types for each beam are shown in Table 2. Beam 3 showed failure in a clear wood section next to a finger joint. This type of failure is mainly attributed to the loss of cross-section due to charring. Beam 4 and 5 showed failure in a knot cluster section. At the same time, also a failure in a clear wood section was observed in these beams. Beam 6 failed due to a finger joint failure and a knot cluster failure. As mentioned earlier, it is not possible to say which type of failure occurred first or which type of failure determined the fire resistance of the beam, respectively. 
a) Side view

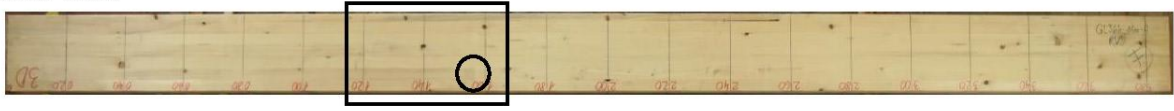

b) Position of finger joint (1)

c) Position of knot cluster
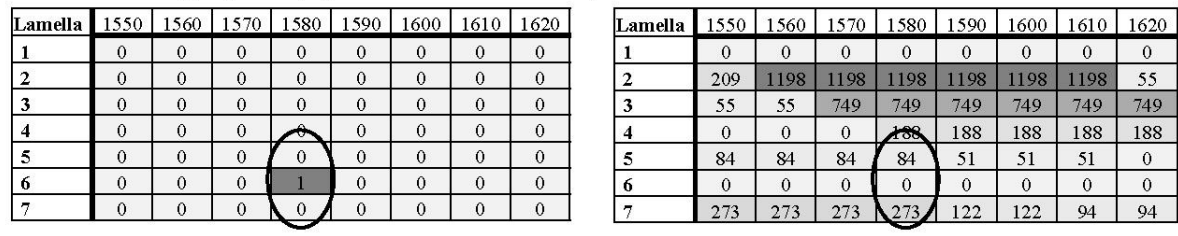

d) Beam details in the area of failure
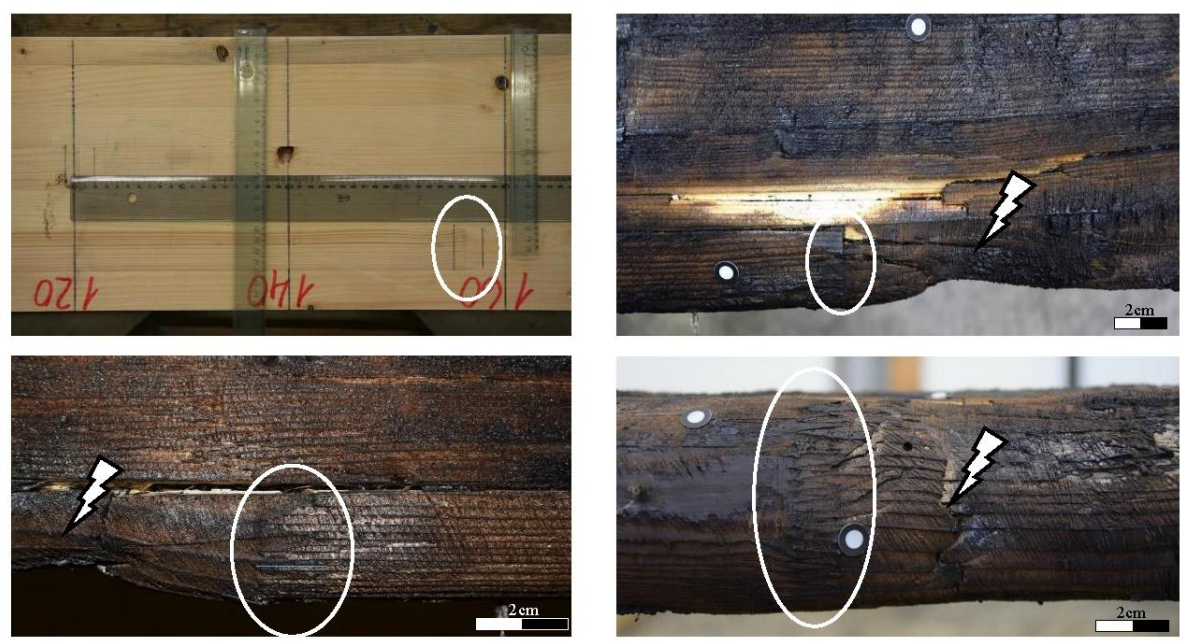

Figure 7. Examination of glulam beam after the fire test using the local material properties. Circles point at the same position in all pictures, lightning marks the failure: a) Side view of glulam beam before testing, $b$ ) Matrix position of finger joint (0: no finger joint, 1: finger joint), c) Matrix of knot cluster based on goldeneye grading (0: clear wood, the greater the value the greater is the knot area in the cross-section, d) beam details in the area of the failure next to the finger joint in a clear wood section.

\subsection{CHARRING BEHAVIOUR}

The residual cross-section of the fire exposed area of each beam was determined at five positions with equal spacing of $200 \mathrm{~mm}$ between them. The middle position was in the middle of the exposed part of the beam. After cutting the beam at these positions, a picture was taken from both faces of each cut and detailed area border lines were retraced using a CAD-software. Figure 8 and Figure 9 show the location of the different cuts and the analysis of the cuts using a CAD software. The location of the centroid of the area and the second moment of inertia were determined using the retraced shape and thus taking into account the true remaining shape. Subsequently, the section moment $W_{f i}$ of the actual shape of the area was calculated elastically (Equation 1).

$$
W_{f i}=\frac{I_{f i}}{Z_{f i, \max }}
$$

Width and height of the residual section were then calculated assuming equal charring depths on all three sides. The resulting mean notional charring rate $\beta_{\mathrm{n}}$ for each specimen is given in Table 2. Its average over all six beams was $0.73 \mathrm{~mm} / \mathrm{min}$, which is in the range of $0.7 \mathrm{~mm} / \mathrm{min}$ given in EN 1995-1-2. For a more detailed comparison with EN 1995-1-2 see section 4. 

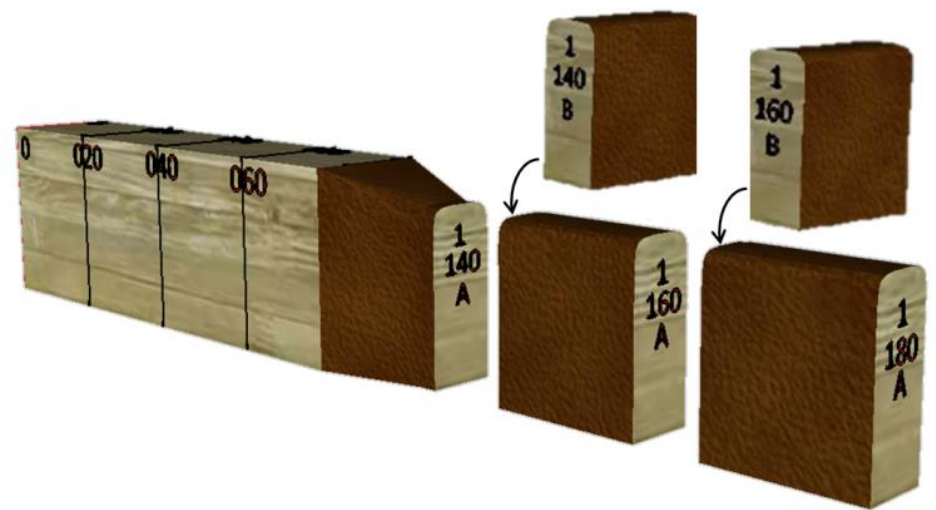

Figure 8. Cuts and numbering of each specimen in $200 \mathrm{~mm}$ distances.

In addition to the notional charring rate $\beta_{\mathrm{n}}$ for each beam, also the one-dimensional basic design charring rate $\beta_{0}$ was determined for each lamella and beam, always taking the mean charring over both sides of each cut (left and right) and over all five cuts. The charring depth was measured in the middle of each lamella as shown in Figure 9, right. The lowest two lamellas were not analyzed as they are fire influenced from more than two opposite sides and thus would not show the one-dimensional basic design charring rate $\beta_{0}$. Table 3 shows the results of this analysis. The one-dimensional basic design charring rate $\beta_{0}$ for the two fire exposed sides of the beams was on average between $0.63 \mathrm{~mm} / \mathrm{min}$ and $0.72 \mathrm{~mm} / \mathrm{min}$.
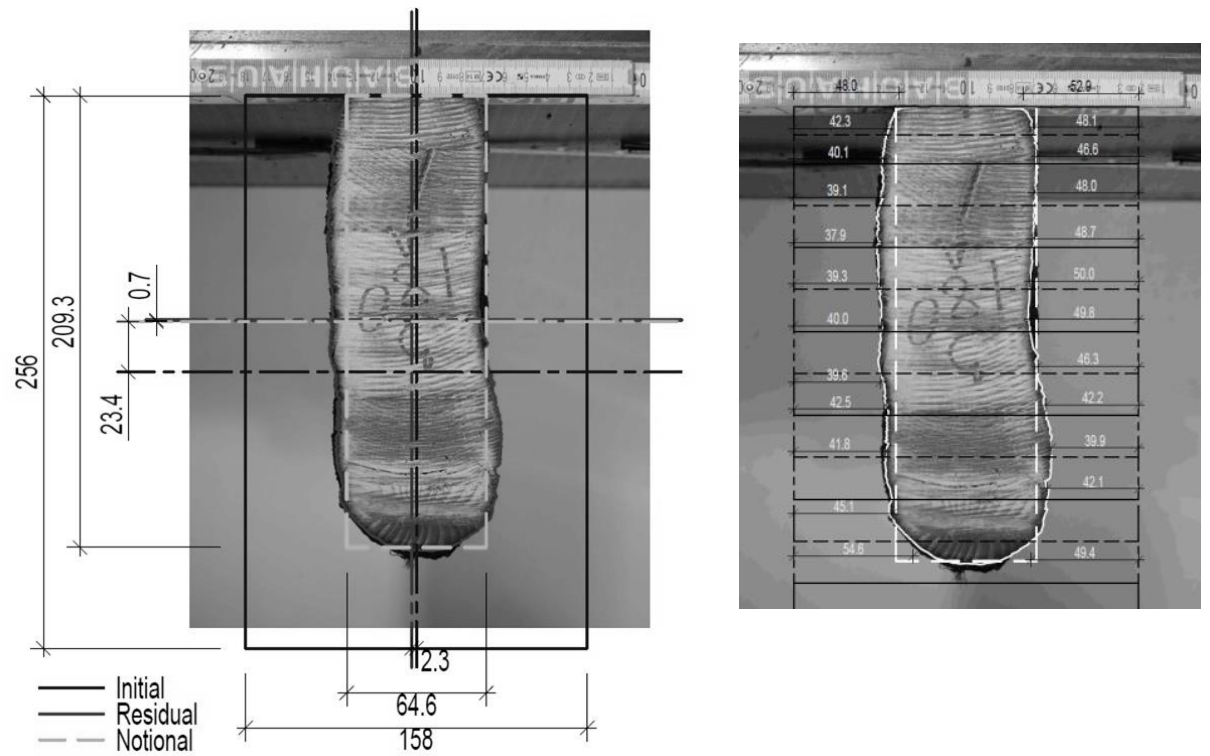

Figure 9. Residual cross-section analyzed with a CAD software, dimensions in [mm].

Table 3. One-dimensional basic design charring rate $\beta_{0}$ for each lamella and specimen

\begin{tabular}{ccccccc}
\hline Lamella & $\begin{array}{c}\text { One-dimensional basic design charring rate } \boldsymbol{\beta}_{\mathbf{0}} \text { as mean over } \\
\text { five cuts with one measurement per side at each cut } \\
\text { [1=topmost) }\end{array}$ & \multicolumn{7}{c}{$\begin{array}{c}\text { [min] } \\
\text { Beam no. }\end{array}$} \\
& $\mathbf{1}$ & $\mathbf{2}$ & $\mathbf{3}$ & $\mathbf{4}$ & $\mathbf{5}$ & $\mathbf{6}$ \\
\hline 1 & 0.73 & 0.77 & 0.65 & 0.74 & 0.71 & 0.72 \\
2 & 0.71 & 0.70 & 0.62 & 0.70 & 0.64 & 0.64 \\
3 & 0.72 & 0.67 & 0.63 & 0.69 & 0.61 & 0.59 \\
4 & 0.74 & 0.67 & 0.62 & 0.66 & 0.61 & 0.60 \\
5 & 0.71 & 0.68 & 0.61 & 0.70 & 0.62 & - \\
\hline Mean & 0.72 & 0.70 & 0.63 & 0.70 & 0.64 & 0.64 \\
\hline
\end{tabular}


Figure 10 shows the one-dimensional basic design charring rate $\beta_{0}$ for charring from the sides of the beam against the density. The data was gathered using the same procedure as explained above, except that each cut and each side was handled separately. Each timber board had only one density for the whole board, as given from the grading device.

Within the 290 data points shown in Figure 10, two groups can roughly be determined: One group consisting of beams 1 and 4, both GL24h (illustrated as crosses), showing a higher charring rate $\beta_{0}$ and a lower density than the second group with the other four beams that were of strength class GL36h (illustrated as shapes).

The correlation between the density and the charring rate $\beta_{0}$ has been discussed controversially in literature (Lache 1992, Röll 1984, Schaffer 1967, Gilka et al. 2010). Analyzing this correlation by fitting (least-square optimization) a trend-line over all points in Figure 10, only a small coefficient of determination $\left(R^{2}\right)$ of 0.131 is achieved, while the correlation coefficient of the sample set is -0.362 . This could lead to the wrong conclusion that the fitted trend-line was not meaningful. However, this cannot be concluded based on the coefficient of determination, as this parameter only gives an information about the scattering around the fitted trend-line and not how confident the trend-line itself is. This information instead can be determined by statistical hypothesis testing. Using a level of significance of $5 \%$ in a $t$-test, upper and lower bounds of the correlation can be calculated, between which the true value lies with a probability of $95 \%$. These bounds are $-6.877 \cdot 10^{-4}(\mathrm{~mm} / \mathrm{min}) /\left(\mathrm{kg} / \mathrm{m}^{3}\right)$ and $6.88344 \cdot 10^{-}$ ${ }_{4}^{4}(\mathrm{~mm} / \mathrm{min}) /\left(\mathrm{kg} / \mathrm{m}^{3}\right)$, respectively. As the bounds of the slope do not contain zero, the null hypothesis of having no correlation between the density and the charring rate $\beta_{0}$ can be rejected and thus the correlation between them is significant. The small bounds allowing this conclusion is the result of the high amount of measurements and the density being known on a smaller scale (lamella) than usual (beam).

Taking the mean density of $466 \mathrm{~kg} / \mathrm{m}^{3}$ and its related mean charring rate of $\beta_{0}=0.672 \mathrm{~mm} / \mathrm{min}$ as references, the charring rate $\beta_{0}$ changes by $10.2 \%$ per $100 \mathrm{~kg} / \mathrm{m}^{3}$ change in the density, which is similar to the $10 \%$ used in Werther (2016). This value is valid only for the tested spruce and might be different for other species. However, assuming that the mass loss rate in a fire is independent of the density, an increase in the latter automatically has to reduce the charring rate $\beta_{0}$, since more mass of timber must be burned per depth. Provided that this is an important justification for the dependency, the dependency must be valid for all species.

Nevertheless, Figure 10 also shows that the scattering is large with a range of maximum $0.246 \mathrm{~mm} / \mathrm{min}$ over ten measurements in the same timber board and thus with the same density. The scattering can be divided virtually into two parts: (1) scattering within one timber board and thus within the same density and (2) scattering of the mean values per density around the fitted trend-line. Taking into account only the scattering of the means at each density, the correlation coefficient increases from formerly -0.362 (see above) to -0.514 and the coefficient of determination of the fitted trend-line $\mathrm{R}^{2}$ increases from 0.131 to 0.264 . The scattering within one density does not necessarily disagree with the overall trend given through the trend-line, since already Just and Tera (2010) noted that the density variation within one timber member can be significant. However, in the present analysis, the density always reflects the mean over one board. Further, this kind of scale effect might be a reason for the controversial literature about charring rates, as it heavily depends on the measuring resolution of the charring depth, the resolution of the density information and the number of measurements. The more global the measurements are, the more difficult it is to find a significant correlation between density and charring. 


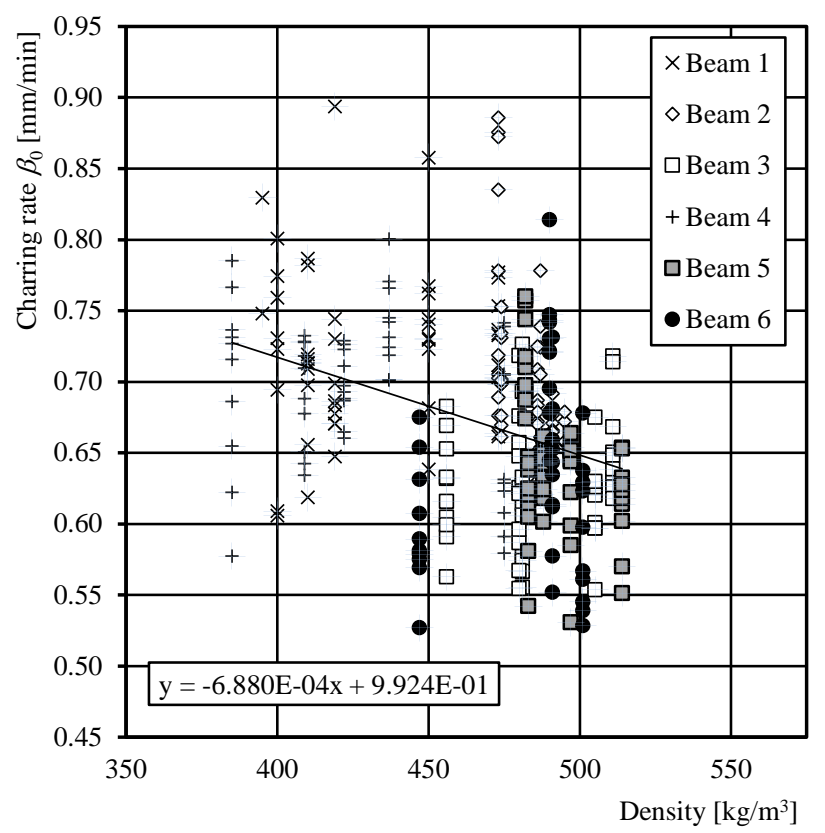

Figure 10. Charring rate $\beta_{0}$ depending on the density of each timber board. Crosses are GL24h, shapes are GL36h

\subsection{DEFLECTION}

Before the fire test was started, the load had been applied, kept constant and the deformation of the beam measured. With this information the beam's Young's modulus $E$ was determined at ambient temperature (Table 4). It was calculated as difference $\Delta F$ between two loads, at which the load-increase was interrupted so that the forces and deformations could settle down. It should be noted that the deformation due to shear was taken into account in order not to underestimate the Young's modulus. The shear modulus was assumed to be $650 \mathrm{MPa}$ independently of the strength class, as given in EN 14080 (2013) respectively prEN 14080.

Table 4. Deflection after load application and before the fire test and calculated Young's modulus $E$

\begin{tabular}{cccccccc}
\hline No & $\begin{array}{c}\text { strENgt } \\
\text { h class }\end{array}$ & $\begin{array}{c}\text { Applied } \\
\text { Load } \boldsymbol{F} \\
{[-]}\end{array}$ & $\begin{array}{c}\Delta \text { Load } \\
\boldsymbol{\Delta} \boldsymbol{F}\end{array}$ & $\begin{array}{c}\boldsymbol{\Delta} \text { Defl. } \\
\text { total } \\
{[\mathbf{k N}]}\end{array}$ & $\begin{array}{c}\boldsymbol{\Delta} \text { Defl. } \\
\text { shear } \\
{[\mathbf{m m}]}\end{array}$ & $\begin{array}{c}\boldsymbol{\Delta} \text { Defl. } \\
\text { bending } \\
{[\mathbf{m m}]}\end{array}$ & $\boldsymbol{E}_{\text {calc }}$ \\
{$[\mathbf{m m}]$} & {$[\mathbf{G P a}]$} \\
\hline 3 & GL36h & 14.21 & 9.07 & 4.52 & 0.65 & 3.88 & 14.58 \\
4 & GL24h & 16.59 & 11.35 & 7.04 & 0.77 & 6.28 & 11.72 \\
5 & GL36h & 21.21 & 14.37 & 7.21 & 0.99 & 6.22 & 15.06 \\
6 & GL36h & 14.61 & 9.45 & 6.93 & 0.79 & 6.14 & 15.91 \\
\hline
\end{tabular}

During the fire tests, the deflection of each beam was measured at different positions (Figure 2). The measurements at the supports could not be positioned at the exact supports, but instead were $70 \mathrm{~mm}$ away from the support's center towards the furnace, so that the span between these two points was $1380 \mathrm{~mm}$. Figure 11 shows the deformation at mid-span of the beams plotted over the time with respect to the supports (left) and to the load applications (right). This differentiation was made since only the center part of the beam was exposed to fire (see Figure 2). Figure 11 shows the deformation increase in the loading phase with the constant deflection for several minutes and the subsequent increase of deformation at constant load during the fire test. During the fire test, the deflection-rate increased over time and tends to infinity at the time of failure, if no sudden and brittle failure occurred before. This can be seen for beams 3 and 5, whereas beams 4 and 6 showed brittle failure. 

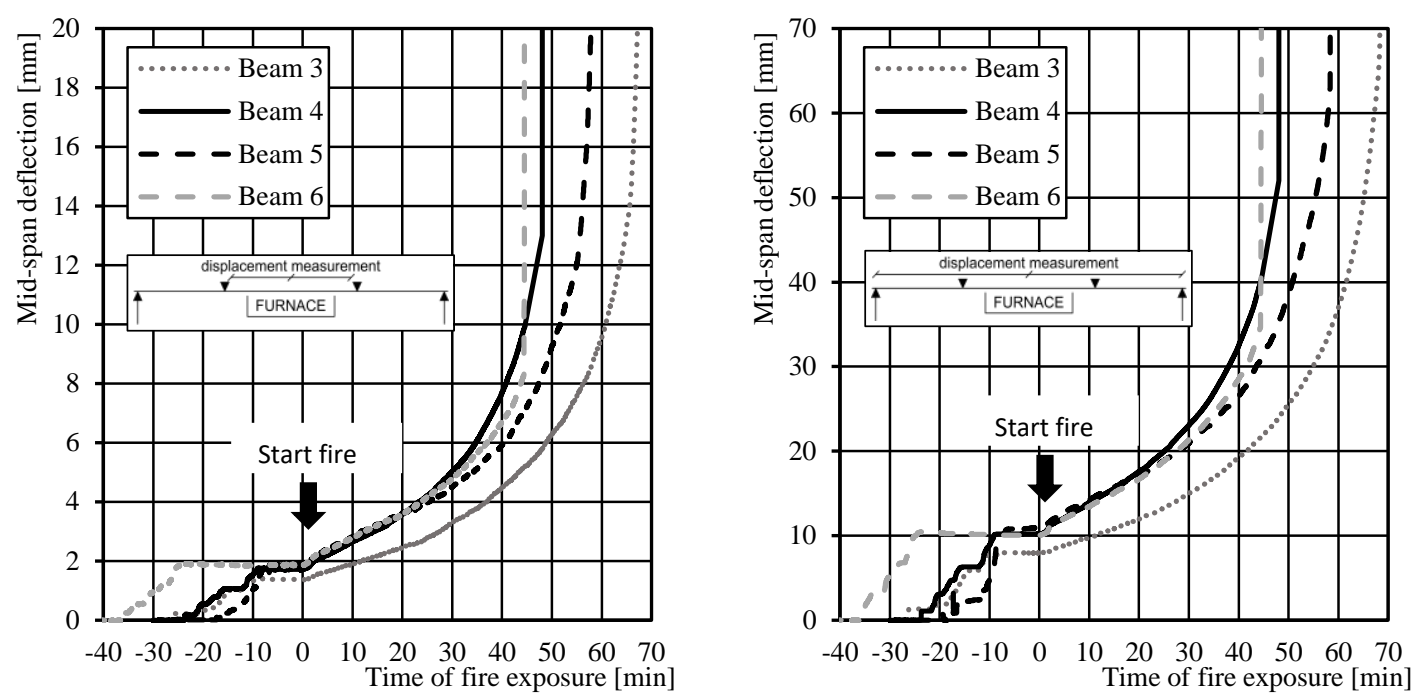

Figure 11. Deflection at mid-span over time of fire exposure, with respect to the supports (left) and to the load application points (right)

The results of the fire resistance tests were compared to calculations using the effective cross-section method according to EN 1995-1-2. It should be noted that this method is currently still named reduced cross-section method, however, it is expected that the name will be changed to effective cross-section method when EN 1995-1-2 is revised. The effective cross-section method is a simplified fire design method for standard fire using a two-step approach to determine the fire resistance via a virtual reduction of the load-bearing cross-section. As presented in Figure 12, the two steps are the following:

1. The original cross-section gets reduced to account for the charring and thereby the residual cross-section is calculated. The charring depth can be calculated by multiplying the fire exposure duration with the so-called 'basic design charring rate $\beta_{0}$ ' (Klippel and Schmid 2017) and few coefficients. The basic design charring rate equals to $\beta_{0}=0.65 \mathrm{~mm} / \mathrm{min}$ and corresponds to the onedimensional charring rate of a solid wood with an infinite width. As the charring at edges and corners with multiple adjacent surfaces exposed to fire is higher than the basic design charring rate $\beta_{0}$, this effect has to be taken into account. The same applies to other effects that depend for example on element dimension and application. Each of these effects are covered in a coefficient $k_{i}$, modifying the basic design charring rate $\beta_{0}$ and together forming the 'notional charring rate' $\beta_{\mathrm{n}}$ (Equation 2). Thereby, all local effects like corner rounding are smeared over the whole surface, which simplifies the calculation of section modulus and moment of inertia (Schmid et al. 2015). Figure 12 left shows the original cross-section, the actual charred cross-section with rounded corners and the simplified, rectangular effective cross-section.

$$
\beta_{n}=\beta_{0} \cdot \prod_{i} k_{i}
$$

2. In the second step of this two-step approach, the reduction of strength and stiffness beneath the char layer due to elevated temperature is considered. Thereby, the residual cross-section, calculated with the notional charring rate $\beta_{\mathrm{n}}$, is further reduced by a so-called 'zero-strength layer $d_{0}{ }^{6}$, giving the 'effective cross-section' (see Figure 12, right). This further reduction does not depend on neither charring rate $\beta_{0}$ nor $\beta_{\mathrm{n}}$, which means that the second step of this approach is independent of the first step and its coefficients. 


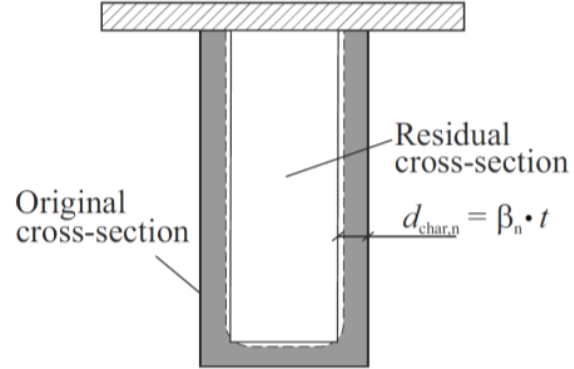

Step 1: Calculation of residual cross-section using the notional charring rate $\beta_{\mathrm{n}}$ and the time of fire exposure $t$

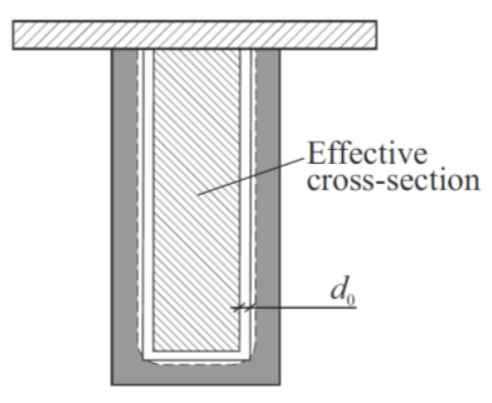

Step 2: Calculation of effective cross-section using the zero-strength layer $d_{0}$

Figure 12. Two-step approach of the effective cross-section method in EN 1995-1-2

In the following, the parameters "notional charring rate $\beta_{\mathrm{n}}$ " used in step 1 of the effective cross-section method and the "zero-strength layer $d_{0}$ " used in step 2 are discussed:

1. EN 1995-1-2 gives a notional charring rate $\beta_{\mathrm{n}}$ of $0.70 \mathrm{~mm} / \mathrm{min}$ for glulam beams with dimensions as tested. As presented in Table 2, the notional charring rate $\beta_{\mathrm{n}}$ in the presented tests ranged from $0.68 \mathrm{~mm} / \mathrm{min}$ to $0.80 \mathrm{~mm} / \mathrm{min}$ with a mean of $0.73 \mathrm{~mm} / \mathrm{min}$, which is close to the value of $0.70 \mathrm{~mm} / \mathrm{min}$ given in EN 1995-1-2. The same applies to the basic design charring rate $\beta_{0}$ (see Table 3), where the mean of $0.67 \mathrm{~mm} / \mathrm{min}$ determined from the fire tests is also slightly higher than $0.65 \mathrm{~mm} / \mathrm{min}$ given in EN 1995-1-2. However, it cannot be concluded that the charring rates in EN 1995-1-2 are too low as the value is valid in general for glulam beams, while the current investigation only investigated beams of two strength classes.

2. EN 1995-1-2 gives a zero-strength layer depth of $7 \mathrm{~mm}$ for glulam beams as tested. Background information and limitations on the determination of the zerostrength layer is well summarized by Schmid et al. (2012) and Schmid et al. (2015). As the zero-strength layer is not a physically measureable property, it needs to be calculated using the following information:

- The mean notional charring rate $\beta_{n}$ (see Table 2)

- The applied load (see Table 2)

- The bending strength at ambient temperature (see Section 2.1); which is 31.2 MPa for GL24h and 39.8 MPa for GL36h

The depth of the zero-strength layer was calculated according to Schmid et al. (2015), whereby Equation 3 needs to be fulfilled.

$$
M_{f i}=M_{e f}=W_{e f} \cdot f_{m}
$$

The bending moment due to loading $M_{\mathrm{fi}}$ must at failure be equal to the bending resistance $M_{\text {ef }}$ of the effective cross-section. Using the mean bending strength $f_{\mathrm{m}}$ of the tested beams at ambient temperature, the zero-strength layer $d_{0}$ was calculated for beam 3 to 6, see Table 5. EN 1995-1-2 gives a zero-strength layer for timber beams in bending of $7 \mathrm{~mm}$. The calculated depth for the zero-strength layer for the tested beams showed considerably different values ranging from $1.5 \mathrm{~mm}$ and $11.8 \mathrm{~mm}$ with a mean value of $6.4 \mathrm{~mm}$.

Table 5. Zero-strength layer depth, calculated with normal/reduced/increased bending strength

\begin{tabular}{cc|ccccc|cc}
\hline $\begin{array}{c}\text { Beam } \\
\text { no. }\end{array}$ & {$[-]$} & 3 & 4 & 5 & 6 & Mean & Mean & Mean \\
\hline $\boldsymbol{d}_{\mathbf{0}}$ & {$[\mathrm{mm}]$} & $7.0 f_{m}$ & $1.0 f_{m}$ & $1.0 f_{m}$ & $1.0 f_{m}$ & $1.0 f_{m}$ & $0.9 f_{m}$ & $1.1 f_{m}$ \\
\hline
\end{tabular}


The scatter in the $d_{0}$-values is directly related to the scattering of the charring process and especially the natural variation of the bending strength. In general, the uncertainties in both charring depth/charring rate and bending strength propagate into the calculated zero-strength layer depth leading to a larger variation of the latter. In the present case of fire experiments, the charring depth was measured and thus the bending strength, best possibly estimated with the bending tests at ambient temperature, is the only uncertain parameter in the calculation of the zero-strength layer. The remaining scattering is still large, but can be expected in this range. To emphasize this, the mean depth of the zero-strength layer was calculated with $10 \%$ reduced/increased bending strength (Table 5, right), which reduced the mean depth of the zero-strength layer by $2.6 \mathrm{~mm} / \mathrm{min}(41 \%)$ to $3.8 \mathrm{~mm} / \mathrm{min}$ and increased it by $2.3 \mathrm{~mm} / \mathrm{min}(36 \%)$ to $8.7 \mathrm{~mm} / \mathrm{min}$, respectively. Similar calculations were done by Schmid et al. (2014). The deviation of the assumed from the true bending strength can be even larger than the $10 \%$ used in the above example, as the bending strength is dominated by the tensile strength of the lowest lamella that is likely to scatter heavily from lamella to lamella. Therefore, the uncertainty in the zero-strength layer depth could be decreased if the local tensile strength of the lowest lamella of each beam were estimated and taken into consideration.

Thus, it will be the next step of this investigation to estimate local strength and stiffness properties using the output of the grading device and applying the model of Fink (2014). These material properties will be used as input for finite element simulations to simulate the beams behavior both at ambient temperature and in fire in accordance to Klippel and Frangi (2017).

Despite the uncertainties present in the current zero-strength layer calculation, the determination of the zero-strength layer can still be regarded as certain according to the definition of Schmid et al. (2014).

\section{5}

\section{CONCLUSION}

This paper presents the results of six fire resistance tests on glulam beams subjected to 4-point bending and exposed to standard EN/ISO fire. The fire tests were performed on the model-scale furnace at the SP fire laboratory in Stockholm with full-size glulam beams.

Before testing, the beams had been thoroughly investigated using a grading device (GoldenEye-706 by MiCROTEC, Giudiceandrea 2005). The finger joint location, weak section location and dimension and the Young's Modulus of each board was documented. Additional reference tests were performed with glulam beams from timber from the same batch to determine the bending strength at ambient temperature (Stadelmann 2015).

After the fire tests, the cross-section of each specimen was thoroughly examined and the one-dimensional basic design charring rate $\beta_{0}$ (mean value $\beta_{0}=0.67$ ) and the notional charring rate $\beta_{\mathrm{n}}$ (mean value $\beta_{\mathrm{n}}=0.73$ ) determined. Using this information together with the time of fire resistance and the bending strength at ambient temperature, the zero-strength layer $d_{0}$ was calculated. Based on four fire tests on glulam beams subjected to bending, a mean zero-strength layer was determined to $6.4 \mathrm{~mm}$ (min value: $1.5 \mathrm{~mm}$; max value: $11.8 \mathrm{~mm}$ ), which is in the order of the zerostrength layer depth according to EN 1995-1-2 (7 mm).

The results of the fire tests will be used for the validation of a probabilistic approach (to be developed) modelling the load-bearing capacity of glued-laminated timber beams under fire exposure with FE-simulations. Thereby, the collected specific local strength and stiffness properties of each glulam beam will be estimated using the model by Fink (2014). As the probabilistic approach can be developed without the need of fire test results (no calibration needed), the available results suffice for the validation.

The authors gratefully acknowledge the support of the European COST Action FP1404 on Fire safe use of bio-based building products. Additionally, the contribution of S. Wynistorf, J. Schmid, and G. Fink is acknowledged. 


\section{REFERENCES}

EN 1363-1:1999. Fire resistance tests - Part 1: General requirements. CEN, Brussels, 1999.

EN 1995-1-2:2004 + AC:2009 (Eurocode 5). Design of timber structures, Part 1-2: General - Structural fire design, CEN, Brussels 2009.

EN 13162:2008. Thermal insulation products for buildings - Factory made mineral wool products - Specification. European Standard. European Committee for Standardization, CEN, Brussels, 2008.

EN 14080:2013. Timber structures - Glued laminated timber and glued solid timberRequirements, CEN, Brussels, 2013.

EN 14081-4:2009. Timber structures - Strength graded structural timber with rectangular cross-section - Part 4: Machine grading - Grading machine settings for machine controlled systems, German version, CEN, Brussels, 2009.

Frangi A. Bemessung von brandabschnittsbildenden Bauteilen in brennbarer Bauweise, Tagungsbeitrag, Forum HolzBauSpezial Akustik \& Brandschutz, 2013.

Fink G. Influence of varying material properties on the load-bearing capacity of glued laminated timber. PhD thesis, Diss., Eidgenössische Technische Hochschule ETH Zürich, Nr. 21746, 2014

Gilka-Bötzow A., Heiduschke A., Haller P.: Zur Abbrandrate von Holz in Abhängigkeit der Rohdichte, European Journal of Wood and Wood Products, Volume 69, Issue 1, page 159 - 162, Springer, 2010.

Giudiceandrea F. Stress grading lumber by a combination of vibration stress waves and x-ray scanning. In: Proceedings of the 11th International Conference on Scanning Technology and Process optimization in the wood Industry (ScanTech 2005), Las Vegas, 2005.

ISO 834-1:1999. Fire - Resistance Tests - Elements of Building Construction - Part 1: General Requirements. International Organization for Standardization, Geneva, 1999.

Just A., Tera T. Variability of Charring Along the Wooden Wall Studs, Statybinès Konstrukcijos ir Technologijos, 2:4, 119-128, 2010.

Klippel M., Schmid J., Frangi A. „Fire design of CLT“ in Proceedings of the Joint Conference of COST Actions FP1402 \& FP1404, Stockholm, ISBN 978-91-799-0438, 2016.

Klippel M., Schmid J. (2017) "Design of Cross-Laminated Timber in Fire", Structural Engineering International 27(2), DOI: https://doi.org/10.2749/101686617X14881932436096.

Klippel M., Frangi A. (2017) Fire Safety of Glued-Laminated Timber Beams in Bending, ASCE Journal of Structural Engineering 143(7), DOI: http://dx.doi.org/10.1061/(ASCE)ST.1943-541X.0001781.

Lache M. Untersuchungen zur Abbrandgeschwindigkeit von Vollholz und zur Feuerwiderstandsdauer biegebeanspruchter BSH-Träger. Institut für Holzforschung der Universität München, 1992.

Lange D., Bostrom L., Schmid J., Albrektsson J. The influence of parametric fire scenarios on structural timber performance and reliability, SP Swedish Technical Research Institute; Report No.2014:35, ISBN978-91-87461-78-1, Borås, Sweden, 2014.

Norén J. Failure of Structural Timber when exposed to fire, Swedish Institute for Wood Technology Research, Report No. 8810066. Stockholm, Sweden, 1988.

Peter M., Gockerl T. Bemessung von Voll- und Brettschichtholzbauteilen aus Maschinell Sortiertem Schnittholz für den Brandfall - Teil 2: Brandversuche zur 
Bestätigung der theoretischen Ergebnisse, Berlin, Institut des Zimmerer- und Holzbaugewerbes e.V., 2006.

prEN 14080:2009. Timber structures - Glued laminated timber and glued solid timber - Requirements, CEN, Brussels, 2009.

Röll H. Untersuchungen über das Abbrandverhalten von Fichten- und Eichenholz in Abhängigkeit von Rohdichte, Jahrringorientierung und Zeit. Forstwiss. Fakultät der Universität Munich, 1984.

Schaffer E.L. Charring rate of selected woods transverse to grain. Forest Service Research Paper FPL 69. Forest Products Laboratory: Madison Winsconsin, 1967.

Schmid J., König J., Just A. The Reduced Cross-Section Method for the Design of Timber Structures Exposed to Fire-Background. Limitations and New Developments,Structural Engineering International 22:514-522, 2012.

Schmid, J., Klippel, M., Just, A., \& Frangi, A. Review and analysis of fire resistance tests of timber members in bending, tension and compression with respect to the reduced cross-section method. Fire safety journal, 68, 81-99, 2014.

Schmid J., Just A., Klippel M., Fragiacomo M. The reduced cross-section method for evaluation of the fire resistance of timber members: discussion and determination of the zero-strength layer. Fire Technology, 51(6), 1285-1309, 2015.

Stadelmann P. Experimental investigations to evaluate the load-bearing behaviour of glued laminated timber with well-known beam setup, Master thesis at ETH Zurich, Switzerland, 2015.

Werther N., Einflussgrössen auf das Abbrandverhalten von Holzbauteilen und deren Berücksichtigung in empirischen und numerischen Beurteilungsverfahren, $\mathrm{PhD}$ thesis, Technische Universität München, 2016. 